\title{
Non-uraninite Products of Microbial U(VI) Reduction
}

\author{
RIZLAN BERNIER-LATMANI, ${ }^{*},+$ \\ HARISH VEERAMANI, ${ }^{\$,}+$ \\ ELENA DALLA VECCHIA, ${ }^{\dagger}$ \\ PILAR JUNIER," $"$, \\ JUAN S. LEZAMA-PACHECO, ‡ \\ ELENA I. SUVOROVA, ${ }^{\dagger}$ \\ JONATHAN O. SHARP,, , \\ NICHOLAS S. WIGGINTON,,${ }^{+}$AND \\ J O H N R B A R A R ${ }^{\ddagger}$ \\ Environmental Microbiology Laboratory, École Polytechnique \\ Fédérale de Lausanne, Lausanne CH 1015, Switzerland, and \\ Stanford Synchrotron Radiation Lightsource, 2575 Sand Hill \\ Road, Menlo Park, California 94025, United States
}

Received May 17, 2010. Revised manuscript received October 5, 2010. Accepted October 13, 2010.

A promising remediation approach to mitigate subsurface uranium contamination is the stimulation of indigenous bacteria to reduce mobile $\mathrm{U}(\mathrm{VI})$ to sparingly soluble U(IV). The product of microbial uranium reduction is often reported as the mineral uraninite. Here, we show that the end products of uranium reduction by several environmentally relevant bacteria (Gram-positive and Gram-negative) and their spores include a variety of U(IV) species other than uraninite. U(IV) products were prepared in chemically variable media and characterized using transmission electron microscopy (TEM) and X-ray absorption spectroscopy (XAS) to elucidate the factors favoring/ inhibiting uraninite formation and to constrain molecular structure/ composition of the non-uraninite reduction products. Molecular complexes of U(IV) were found to be bound to biomass, most likely through P-containing ligands. Minor U(IV)-orthophosphates such as ningyoite $\left[\mathrm{CaU}\left(\mathrm{PO}_{4}\right)_{2}\right], \mathrm{U}_{2} \mathrm{O}\left(\mathrm{PO}_{4}\right)_{2}$, and $\mathrm{U}_{2}\left(\mathrm{PO}_{4}\right)\left(\mathrm{P}_{3} \mathrm{O}_{10}\right)$ were observed in addition to uraninite. Although factors controlling the predominance of these species are complex, the presence of various solutes was found to generally inhibit uraninite formation. These results suggest a new paradigm for U(IV) in the subsurface, i.e., that non-uraninite U(IV) products may be found more commonly than anticipated. These findings are relevant for bioremediation strategies and underscore the need for characterizing the stability of non-uraninite U(IV) species in natural settings.

\section{Introduction}

As a legacy of the Cold War that involved the mining, milling, and processing of uranium at large scales at numerous sites

\footnotetext{
* Corresponding author phone: 4121 693-5001; fax: 4121 6936205; e-mail: rizlan.bernier-latmani@epfl.ch.

${ }^{\dagger}$ École Polytechnique Fédérale de Lausanne.

${ }^{\$}$ Current address: Department of Geosciences, Virginia Tech, Blacksburg, VA 24061.

"Current address: Laboratory of Microbiology, University of Neuchâtel, Neuchâtel 2000, Switzerland.

${ }^{\ddagger}$ Stanford Synchrotron Radiation Lightsource.

${ }^{\perp}$ Current address: Environmental Science and Engineering, Colorado School of Mines, Golden, CO 80401.

\# Current address: Science, 1200 New York Avenue NW, Washington, D.C., 20005.
}

in the United States and former Eastern European states, uranium contamination of the subsurface is of significant environmental and public health concern. Bioremediation is proposed as one potential approach to mitigate this contamination because of its perceived cost-effectiveness. A typical bioimmobilization effort would involve the stimulation of indigenous bacteria in situ in order to transform and immobilize soluble U(VI) to immobile U(IV) species, which are often thought to be dominated by the mineral uraninite (1). In fact, uranium bioreduction and uraninite formation have been demonstrated in batch experiments for a variety of Gram-negative bacteria: Shewanella spp., Geobacter spp., Desulfovibrio spp. and Anaeromyxobacterspp. (2-4), a Grampositive bacterium, Desulfosporosinus sp. (5), and in situ biostimulated sediments from the Oak Ridge IFRC site $(6,7)$.

Uraninite is generally regarded as the most desirable product of bioreduction due to its low solubility under reducing conditions (8). A structural characterization of biogenic nanoparticulate uraninite produced under geochemically similar conditions by Gram-negative bacterial genera including Shewanella, Geobacter, Desulfovibrio, and Anaeromyxobacter demonstrated the structural homology of the product regardless of the phylogeny $(9,10)$.

However, evidence that non-uraninite U(IV) can be produced by microbially mediated $\mathrm{U}(\mathrm{VI})$ reduction is emerging from both laboratory and field-scale experiments. The reduction of a $U(V I)$-phosphate mineral phase by the bacterium Thermoterrabacterium ferrireducens lead to the formation of a $\mathrm{U}(\mathrm{IV})$ mineral ningyoite, $\mathrm{CaU}\left(\mathrm{PO}_{4}\right)_{2}$, rather than uraninite (11). Furthermore, batch experiments have demonstrated that the reduction of $\mathrm{U}(\mathrm{VI})$-citrate complexes by Clostridium species formed stable U(IV) solution complexes (12). Researchers have recently reported the formation of a phase or mineral distinct from $\mathrm{UO}_{2}$ and composed of mononuclear U(IV) atoms surrounded by light elements as a result of $U(\mathrm{VI})$ reduction by Desulfitobacterium spp. (13). Several researchers have also reported the formation, in natural systems, of U(IV) species lacking an X-ray absorption spectroscopy (XAS) feature (a U-U shell at $3.85 \AA$ ) characteristic of the mineral uraninite, including the product of biostimulated $\mathrm{U}(\mathrm{VI})$ reduction in Oak Ridge sediments (7), sediment from a naturally reduced zone at the Rifle IFRC (Kate Campbell, personal communication) and the product of $\mathrm{U}(\mathrm{VI})$ reduction by an isolate from the Rifle IFRC site (A. Ray, personal communication). Most recently, a study showed that some of the reduced $U$ in microcosms containing Oak Ridge IFRC site sediments and incubated with $\mathrm{H}_{2}$ for 11 months was present as U(IV) bound to Fe (6).

These observations raise two related questions: (a) what is the structure and composition of non-uraninite U(IV) and (b) what variables control the preferential formation of uraninite vs non-uraninite U(IV)? We postulated that nonuraninite U(IV) includes molecular U(IV) complexed to biomass or minerals and that geochemical composition rather than biological variability controls the formation of uraninite. To test these hypotheses, we investigated the product of enzymatic U(VI) reduction by Gram-positive (Desulfotomaculum reducens $\mathrm{MI}-1$ and Clostridium acetobutylicum (ATCC 824)) and Gram-negative (Shewanella oneidensis MR-1) bacteria. Due to the limited geochemical conditions that support U(VI) reduction by these Grampositive bacteria, only $S$. oneidensis enabled a comparison of the effect of various incubation media on the products of $\mathrm{U}(\mathrm{VI})$ reduction. We report three primary results: (1) uraninite formation is inhibited under certain geochemical conditions; (2) phylogenetically distinct bacteria can produce biomass- 


\section{TABLE 1. Samples Considered for the Study ${ }^{a}$}

\begin{tabular}{cl} 
sample name & \multicolumn{1}{c}{ bacterium } \\
A & S. oneidensis \\
B & S. oneidensis \\
C & S. oneidensis \\
D & S. oneidensis \\
E & C. acetobutylicum \\
F & C. acetobutylicum \\
G & C. acetobutylicum \\
H & D. reducens \\
I & D. reducens
\end{tabular}

cells or spores
cells
cells
cells
cells
spores
cells
cells
cells
spores

$\begin{array}{lc}\text { medium } & \text { U(VI) conc }(\boldsymbol{\mu} \mathbf{M}) \\ \text { BP } & 500 \\ \text { fresh WLP } & 400 \\ \text { spent WLP } & 400 \\ \text { spent WLP } & 100 \\ \text { spent FLP } & 150 \\ \text { spent FLP } & 150 \\ \text { spent FLP } & 150 \\ \text { spent WLP } & 150 \\ \text { spent WLP } & 300\end{array}$

\begin{tabular}{cl} 
0D600 & \multicolumn{1}{c}{ analysis } \\
1 & XAS, TEM \\
1 & XAS, TEM \\
1 & XAS \\
3 & XAS \\
NA & XAS, TEM \\
0.2 & XAS, TEM \\
0.5 & XAS \\
0.2 & XAS, TEM \\
NA & XAS, TEM
\end{tabular}

${ }^{a}$ Media used for various conditions are described in the text. $\mathrm{OD}_{600}$ refers to optical density of the cell culture used for $\mathrm{U}(\mathrm{VI})$ reduction. Spore concentration in reduction assay: D. reducens $\left(1.6 \times 10^{8}\right.$ per $\left.\mathrm{mL}\right)$, C. acetobutylicum $\left(3.7 \times 10^{7}\right.$ per $\mathrm{mL})$.

associated U(IV) complexes (referred to as 'molecular U(IV)') and (3) other reduced U(IV) products were observed in addition to molecular $\mathrm{U}(\mathrm{IV})$ : ningyoite, $\mathrm{U}_{2} \mathrm{O}\left(\mathrm{PO}_{4}\right)_{2}$, $\mathrm{U}_{2}\left(\mathrm{PO}_{4}\right)\left(\mathrm{P}_{3} \mathrm{O}_{10}\right)$, and uraninite.

\section{Materials and Methods}

Cellular Culture and Growth. Clostridium acetobutylicum (DSM 792) culture was purchased from DSMZ and cultured anaerobically in a modified medium (14) that we dubbed Francis Low Phosphate (FLP) basal medium (Supporting Information Table SI-1) amended with $0.025 \%$ (v/v) glycerol, $28 \mathrm{mM}$ glucose, and $0.1 \mathrm{~g} / \mathrm{L}$ peptone. Desulfotomaculum reducens strain MI-1 was grown anaerobically in Widdel low phosphate (WLP) basal medium (modified from ref 15) amended with vitamins and trace elements (Tables SI- 1 and SI-2) and pyruvate (10 $\mathrm{mM})$ as a fermentative substrate. The $\mathrm{pH}$ values of the basal FLP and WLP media were 6.8 and 7.3, respectively, and were measured to be $7.0 \pm 0.3$ after amendments and prior to inoculation. Shewanella oneidensis MR-1 was grown aerobically in LB (Luria Bertani) medium as described previously (16).

U(VI) Reduction by Various Cultures. All experimental manipulations were carried out inside an anaerobic chamber (COY Laboratory Products, Inc., Grass Lake, MI). All reagents were obtained from Sigma-Aldrich unless otherwise indicated. $\mathrm{U}(\mathrm{VI})$ reduction by the various bacteria is described below. A key to sample labels is provided in Table 1 .

D. reducens. For vegetative cell-mediated U(VI) reduction, a culture was grown in the presence of U(VI), and the sample collected after complete reduction (sample H). Reduction of $\mathrm{U}(\mathrm{VI})$ by spores was carried out by the addition of a spore preparation to spent WLP medium. Spent medium was found to be necessary to support spore-mediated U(VI) reduction (17) and was obtained as follows: after the depletion of pyruvate, cells and spores were removed from a pyruvategrown culture by centrifugation. The supernatant was filtersterilized in the anaerobic chamber $\left(5 \% \mathrm{H}_{2}\right)$ and transferred anaerobically to a new sterile container. The spent WLP medium was aliquoted to sterile serum bottles and amended with $20 \mathrm{mM} \mathrm{H}_{2}$ and $100-300 \mu \mathrm{M}$ anaerobic $\mathrm{U}(\mathrm{VI})$ as uranyl acetate. Phosphate content in spent WLP medium was measured and found to be $48 \pm 0.6 \mathrm{mg} / \mathrm{L}$ as compared to 51 $\pm 1.5 \mathrm{mg} / \mathrm{L}$ for fresh WLP (the higher concentration than the reported medium composition $(21 \mathrm{mg} / \mathrm{L}$ ) in Table SI- 1 is due to yeast extract contributions). Spore preparations were obtained by exposure of a fermentatively grown culture to $20 \mathrm{mM}$ acetate and $1 \mathrm{mM}$ sulfate for several weeks until a large proportion ( $\sim 50 \%$ ) of cells had sporulated. The resulting spores were washed once in oxic water and three times in anaerobic water and resuspended (at a concentration of 1.6 $\times 10^{8}$ spores $/ \mathrm{mL}$ ) in anaerobic water before the reduction experiments (17). Dissolved U(VI) was monitored in all cases.

C. acetobutylicum. U(VI) reduction by cells was carried out by collecting cells from a culture that had reached stationary phase and resuspending them, at the appropriate cell density, in spent FLP medium amended with $20 \mathrm{mM} \mathrm{H}_{2}$, 20 mM MES (2-(N-morpholino)ethanesulfonic acid) buffer, $30 \mathrm{mM}$ bicarbonate and $100 \mu \mathrm{M} \mathrm{U}(\mathrm{VI})$. Spent FLP medium was obtained by collecting the supernatant of a C. acetobutylicum culture similarly to spent WLP medium. Phosphate content in spent FLP medium was measured to be $15 \pm 0.0$ $\mathrm{mg} / \mathrm{L}$ as compared to $30.3 \pm 0.5 \mathrm{mg} / \mathrm{L}$ for fresh FLP. U(VI) reduction by spores was initiated by adding spores $\left(3.7 \times 10^{7}\right.$ per $\mathrm{mL}$ final concentration) to a serum bottle containing spent FLP medium amended with $20 \mathrm{mM} \mathrm{H}_{2}, 20 \mathrm{mM}$ PIPES (piperazine-1,4-bis-2-ethanesulfonic acid), $30 \mathrm{mM}$ bicarbonate, and $150 \mu \mathrm{M} \mathrm{U}(\mathrm{VI})$. The addition of bicarbonate at that concentration is in line with the alkalinity observed during biostimulation at the Old Rifle field site in Colorado (K. Williams, personal communication). The spore preparation was obtained by heat-shocking a late-log phase culture through alternating incubation at $40{ }^{\circ} \mathrm{C}(23 \mathrm{~h})$ and $4{ }^{\circ} \mathrm{C}(1$ $\mathrm{h}$ ) and repeated centrifugation and washing in aerobic Milli-Q (18 M $\Omega . c m)$ water.

S. oneidensis. Cultures grown in LB were collected by centrifugation and washed in the appropriate basal medium, either WLP or a simple medium composed of $20 \mathrm{mM}$ PIPES and $30 \mathrm{mM}$ sodium bicarbonate (BP). Reduction assays were initiated by resuspending the washed culture cell suspension in either WLP (fresh or spent) medium or BP anoxic basal medium containing $20 \mathrm{mM} \mathrm{H}_{2}$ and amending it with $500 \mu \mathrm{M}$ uranyl acetate. While $S$. oneidensis is versatile and reduces $\mathrm{U}(\mathrm{VI})$ in BP or WLP, C. acetobutylicum and D. reducens were found to only reduce $\mathrm{U}(\mathrm{VI})$ in their respective media.

Analytical. Aqueous U(VI) concentration was measured by kinetic phosphorescence analysis (KPA-11; Chemcheck Instruments, Richland, WA) after anaerobic filtration (Millipore Millex-GV PVDF $0.2 \mu \mathrm{m}$ ). Phosphate concentration was measured spectrophotometrically by a modified ascorbic acid method $(18,19)$.

Electron Microscopy. Samples for electron microscopy were prepared by fixing the bacterial cells or spores in glutaraldehyde and dehydrating them sequentially in pure grade ethanol (Fluka). The fixed dehydrated cells or spores were then centrifuged and the pellet immobilized in LRWhite resin (Electron Microscopy Science, Hatfield, PA, USA), which was polymerized at $60^{\circ} \mathrm{C}$. This procedure was carried out inside an anaerobic chamber to prevent sample oxidation. Thin sections of the resin were cut using an ultracut ultramicrotome (Reichert-Jung) and an ultrasonic (oscillating) $35^{\circ} \mathrm{knife}$ from Diatome (Biel, Switzerland). Thin sections were placed on copper grids (Quantifoil Micro Tools, $\mathrm{GmbH}$ Jena). Low dose illumination conditions were used to record the images in order to limit sintering of particles under the electron beam.

Conventional bright field transmission electron microscopy (TEM), high-resolution TEM (HRTEM), and selected area electron diffraction (SAED) was performed with a FEI 
CM300UT/FEG microscope (Eindhoven, Netherlands). Images were recorded on a Gatan 797 slow scan CCD camera (1024 pixels $\times 1024$ pixels $\times 14$ bits) and processed with the Gatan Digital Micrograph 3.11.0 software (Gatan, Inc., Pleasanton, CA, USA), including Fourier transformation (FT) and filtering. Phase identification was derived from SAED patterns collected on the CCD and Fourier transforms of the HRTEM images using JEMS software (20).

Direct chemical information was obtained by X-ray energy dispersive spectroscopy (EDS). The distribution of elements over a particular area of the sample was viewed using element maps in scanning transmission electron microscopy (STEM) mode and interpreted with the INCA (Oxford) software. Quantification was performed with the QuantMap software application designed to generate quantitative elemental maps from SmartMap data. The quantitative data are calculated from spectral data stored at each pixel of the SmartMap.

X-ray Absorption Spectroscopy (XAS). XAS analysis included X-ray absorption near edge structure (XANES) and extended X-ray absorption fine structure (EXAFS) spectroscopy. Sample pellets collected by centrifugation and removal of the supernatant were sealed under an anaerobic atmosphere ( $2-5 \%$ hydrogen, balance nitrogen) and delivered to SSRL in a hermetically sealed stainless steel container (Schuett-biotec GmbH, Göttingen, Germany) for anaerobic loading and analysis. All sample-loading operations were conducted under anoxic conditions inside an anaerobic chamber. Wet samples were pelleted and loaded in $\mathrm{Al}$ sample holders with Kapton windows. Sample assemblies were stored in the anaerobic chamber until immediately prior to analysis, at which point they were mounted in a liquid $\mathrm{N}_{2}$ cryostat, placed under vacuum, and frozen. $\mathrm{U} \mathrm{L}_{\mathrm{III}}$-edge transmission or fluorescence spectra were collected at SSRL beamlines 11-2 and 10-2, using Si (220) double-crystal monochromators detuned to reject higher harmonic intensity. Energy resolution was maintained at less than the $8.67 \mathrm{eV}$ natural line width of the $\mathrm{U}_{\mathrm{III}}$-edge using vertical slits. Samples were analyzed at $77 \mathrm{~K}$. EXAFS spectra were background subtracted, splined, and analyzed using ARTEMIS (21). XANES spectra were fit with a linear combination of spectra from autunite $\left(\mathrm{Ca}\left(\mathrm{UO}_{2}\right)_{2}\left(\mathrm{PO}_{4}\right)_{2} \bullet 10-12\left(\mathrm{H}_{2} \mathrm{O}\right)\right), \mathrm{UO}_{2.00}$, and $\mathrm{U}(\mathrm{IV})$ sorbed on hydroxyl apatite, provided by C. Fuller, USGS, Menlo Park. The oxidation state in this sample was verified by digestion in $\mathrm{HCl}$, passing the effluent through an anion exchange resin (AG1-X8 Cl form), and subsequently eluting the U(IV) bound in the column, as well as by XANES fitting with $\mathrm{UO}_{2.00}$. Backscattering phase and amplitude functions required for fitting of spectra were obtained from FEFF8 (22).

\section{Results and Discussion}

$\mathbf{U}(\mathrm{VI})$ Reduction. The reduction of U(VI) proceeded in all the cases considered (Figure SI-1). This is the first instance in which spores of $C$. acetobutylicum were found to reduce $\mathrm{U}(\mathrm{VI})$, but it is consistent with the recently reported reduction of $\mathrm{U}(\mathrm{VI})$ by spores of $D$. reducens, another member of the Clostridiales (17). The rate of U(VI) reduction by C. acetobutylicum spores appears to be significantly slower than that by D. reducens spores (Figure SI-1). U(VI) disappearance from solution is faster in the presence of $C$. acetobutylicum cells, but some of the initial removal of solution U(VI) is attributable to sorption onto the cell biomass whereas the sustained removal is due to reduction (Figure SI-1). Reduction of U(VI) by $S$. oneidensis in BP is also rapid (complete within $48 \mathrm{~h}$ ). Rates of U(VI) reduction in WLP by $S$. oneidensis cells and $D$. reducens spores and cells were comparable and corresponded to an intermediate between that of C. acetobutylicum spores and that of $S$. oneidensis cells in BP (complete reduction in $\sim 100 \mathrm{~h}$ ). In all cases, uranium reduction had the net effect of removing $\mathrm{U}(\mathrm{VI})$ from solution and producing biomass-associated $U$ that was collected by centrifugation.
Evidence for the Presence or Absence of Uraninite. Analysis of the XANES data shows that within the error of the technique $(\sim 10 \%)(23), \mathrm{U}$ is present in all samples in the reduced, U(IV) state (Figure SI-2). Visual inspection of the Fourier transforms (FTs) of the EXAFS data (Figure 1) shows that samples B, C, D, H, and I (corresponding to the S. oneidensis and $D$. reducens samples in WLP- see Table 1) lack the U-U peak at $3.85 \AA$ that is characteristic of uraninite. In contrast, a frequency of varying intensity is present in FTs for samples A, E, F, and G (the latter three corresponding to C. acetobutylicum spore-only and cell-only samples in FLPTable 1) at $\sim 3.85 \AA$. U shells at 3.8 to $3.9 \AA$ provided good fits to this feature, suggesting it to be a $\mathrm{U}-\mathrm{U}$ pair correlation (Table 2). U-U frequencies at this distance are frequently (but not necessarily) due to the presence of (nano)crystalline uraninite. For samples A and E, transmission electron microscopy (TEM) images and selected area diffraction (SAED) diffraction patterns confirmed the presence of uraninite (Figure 2A and Figure SI-3C). Sample F exhibits the weakest (putative) $\mathrm{U}-\mathrm{U}$ shell of the three Clostridium samples. The similarity of the samples suggests $U$ as the most reasonable interpretation for this shell. However, TEM did not reveal any uraninite in this sample (Figure SI-3D) despite the expectation that it would be detectable. Thus, an alternative explanation is required for the $U-U$ shell in sample F. Plausible explanations include the presence of multimeric molecular U(IV) species or of a noncrystalline (i.e., nondiffracting) nanosolid phase. No evidence for uraninite was observed in samples I, H, and B by TEM and SAED (Figure 2B, Figures SI-3A and SI-3B), consistent with the XAS data for those samples.

In summary, we observe that many samples contain forms of U(IV) other than uraninite. Thus, while the product of $\mathrm{U}(\mathrm{VI})$ reduction by bacteria is often assumed to be uraninite (24), it is clear that other products also form. This observation prompted us to investigate the physical and chemical forms of non-uraninite U(IV) species and to consider the factors that may favor/inhibit uraninite formation.

Structure and Composition of the U(IV) Species. A priori, one might expect that the non-uraninite U(IV) species could be complexed by the abundant functional groups on cell biomass (25) or precipitated as phases other than uraninite. We used TEM and further analysis of the EXAFS data to constrain the structures and morphologies of U(IV) in the samples. General details about EXAFS fitting and fit results are provided in the SI (section SI-1) and key points are summarized below.

Crystalline $U(I V)-O r t h o p h o s p h a t e s$. Three crystalline U(IV)-orthophosphates were identified by SAED: ningyoite $\left(\mathrm{CaU}\left(\mathrm{PO}_{4}\right)_{2}\right), \mathrm{U}_{2} \mathrm{O}\left(\mathrm{PO}_{4}\right)_{2}$, and $\mathrm{U}_{2}\left(\mathrm{PO}_{4}\right)\left(\mathrm{P}_{3} \mathrm{O}_{10}\right)$.

Two of those phases -ningyoite and $\mathrm{U}_{2} \mathrm{O}\left(\mathrm{PO}_{4}\right)_{2}$ - were associated with $D$. reducens spores (sample I) (Figure SI-3A). The presence of ningyoite was corroborated by EDS as U, P, and Ca were strongly colocalized (Figure SI-4). This mineral has also been reported to form through the reduction of a $\mathrm{U}(\mathrm{VI})$-phosphate solid by the Gram-positive bacterium Thermoterrabacterium ferrireducens (11). For this solid, we would expect $3 \mathrm{U}-\mathrm{Ca}$ correlations at $\sim 3.85 \AA$ (26). However, these were not observed in the corresponding EXAFS spectrum, and this absence is consistent with relatively low bulk abundance of the solid. We therefore conclude that ningyoite is a minority phase in this sample. Interestingly, there was no detectable ningyoite in the C. acetobutylicum samples despite the fact that $\mathrm{Ca}^{2+}$ is present at a concentration five times greater in FLP than in WLP (Table SI-1). Ningyoite formation exclusively in the $D$. reducens spore system may be linked to the observed loss of $D$. reducens spore integrity after $\mathrm{U}(\mathrm{VI})$ reduction. High concentrations of the $\mathrm{Ca}^{2+}$. dipicolinic acid complex are present in the spore core (27) 

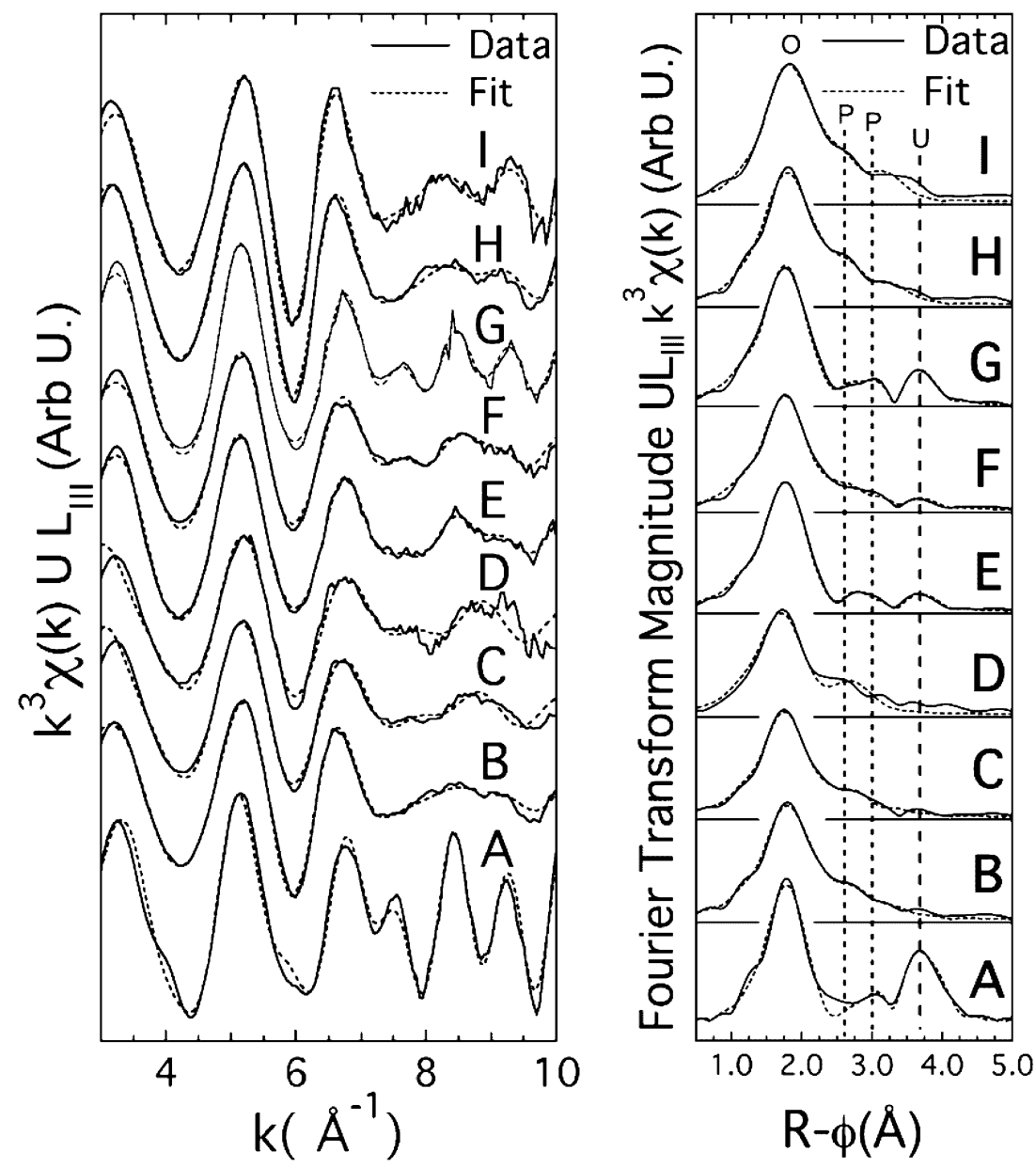

FIGURE 1. EXAFS data (left-hand side) and corresponding Fourier transforms (right-hand side) for samples A through I, listed in Table 1. The vertical dashed line marks the location of backscattering shell frequencies.

TABLE 2. EXAFS Fits ${ }^{a}$

\begin{tabular}{|c|c|c|c|c|c|c|c|c|c|c|}
\hline & & & S. one & Iensis & & & acetobutylic & & D. re & ucens \\
\hline & & $A$ & B & C & D & $E$ & $F$ & G & $\mathrm{H}$ & 1 \\
\hline$U-O$ & $\begin{array}{l}N \\
R(\AA) \\
\sigma^{2}\left(\AA^{2}\right)\end{array}$ & $\begin{array}{l}8.0 \pm 1.0 \\
2.35(1) \\
0.014(2)\end{array}$ & $\begin{array}{l}9.3 \pm 1.3 \\
2.37(1) \\
0.018(2)\end{array}$ & $\begin{array}{l}7.8 \pm 0.9 \\
2.34(1) \\
0.017(2)\end{array}$ & $\begin{array}{l}8.1 \pm 1.2 \\
2.30(2) \\
0.018(2)\end{array}$ & $\begin{array}{l}8.7 \pm 0.9 \\
2.36(1) \\
0.017(2)\end{array}$ & $\begin{array}{l}8.3 \pm 0.9 \\
2.35(1) \\
0.018(2)\end{array}$ & $\begin{array}{l}10.3 \pm 1.5 \\
2.36(1) \\
0.018(2)\end{array}$ & $\begin{array}{l}12.5 \pm 2.2 \\
2.37(2) \\
0.020(3)\end{array}$ & $\begin{array}{l}10.9 \pm 3.9 \\
2.37(2) \\
0.018(3)\end{array}$ \\
\hline$U-P$ & $\begin{array}{l}N \\
R(\AA) \\
\sigma^{2}\left(\AA^{2}\right)\end{array}$ & & $\begin{array}{l}3.4 \pm 1.2 \\
3.12(3) \\
0.013(3)\end{array}$ & $\begin{array}{l}2.1 \pm 0.2 \\
3.12(3) \\
0.010(4)\end{array}$ & $\begin{array}{l}1.3 \pm 0.8 \\
3.08(62) \\
0.006(6)\end{array}$ & $\begin{array}{l}0.7 \pm 0.6 \\
3.15(3) \\
0.005(10)\end{array}$ & $\begin{array}{l}0.9 \pm 0.9 \\
3.12(2) \\
0.004(9)\end{array}$ & $\begin{array}{l}0.8 \pm 1.1 \\
3.14(3) \\
0.004(13)\end{array}$ & $\begin{array}{l}4.8 \pm 2.1 \\
3.11(2) \\
0.014(4)\end{array}$ & $\begin{array}{l}3.5 \pm 2.9 \\
3.05(6) \\
0.010(7)\end{array}$ \\
\hline$U-P$ & $\begin{array}{l}N \\
R(\AA) \\
\sigma^{2}\left(\AA^{2}\right)\end{array}$ & & $\begin{array}{l}1.6 \pm 0.4 \\
3.72(2) \\
0.010(f)\end{array}$ & $\begin{array}{l}1.0 \pm 0.4 \\
3.73(3) \\
0.010(f)\end{array}$ & $\begin{array}{l}2.2 \pm 0.7 \\
3.62(3) \\
0.010(f)\end{array}$ & $\begin{array}{l}1.7 \pm 4.3 \\
3.78(6) \\
0.017(3)\end{array}$ & $\begin{array}{l}1.4 \pm 2.0 \\
3.68(2) \\
0.008(12)\end{array}$ & $\begin{array}{l}2.1 \pm 1.6 \\
3.75(3) \\
0.010(f)\end{array}$ & $\begin{array}{l}2.2 \pm 0.6 \\
3.73(3) \\
0.010(f)\end{array}$ & $\begin{array}{l}3.4 \pm 1.0 \\
3.68(2) \\
0.010(f)\end{array}$ \\
\hline$U-U$ & $\begin{array}{l}N \\
R(\AA) \\
\sigma^{2}\left(\AA^{2}\right)\end{array}$ & $\begin{array}{l}10.5 \pm 2.0 \\
3.88(2) \\
0.010 \text { (f) }\end{array}$ & & & & $\begin{array}{l}1.6 \pm 0.5 \\
3.81(7) \\
0.010(f)\end{array}$ & $\begin{array}{l}1.0 \pm 0.4 \\
3.77(10) \\
0.010(f)\end{array}$ & $\begin{array}{l}3.4 \pm 0.8 \\
3.79(6) \\
0.010(f)\end{array}$ & & \\
\hline$U-O$ & $\begin{array}{l}N \\
R(\AA) \\
\sigma^{2}\left(\AA^{2}\right)\end{array}$ & $\begin{array}{l}24(f) \\
4.47(4) \\
0.015(16)\end{array}$ & & & & & & & & \\
\hline
\end{tabular}

${ }^{a} N$ is the coordination number, $R$ is the interatomic distance, and $\sigma^{2}$ is the Debye-Waller factor. (f) indicates that this parameter was fixed. Shells at 3.1 and $3.7 \AA$ A were attributed to $U-P$ but are also compatible with $U-C$ (section SI-1).

and could be released after loss of spore integrity creating microenvironments in which $\left[\mathrm{Ca}^{2+}\right]$ exceeds the solubility of ningyoite.

In addition to ningyoite, $\mathrm{U}_{2} \mathrm{O}\left(\mathrm{PO}_{4}\right)_{2}$ was also identified in sample I. The same phase was detected in sample $\mathrm{F}$ using SAED (cf., Figure SI-3D). The $\mathrm{U}_{2} \mathrm{O}\left(\mathrm{PO}_{4}\right)_{2}$ structure contains $\mathrm{U}-\mathrm{P}$ pairs at $3.1 \AA$ (with a coordination number $(\mathrm{CN})$ of 1 ) as well as four P atoms at distances 3.74-3.83 $\AA$ (28). Shellby-shell fits to EXAFS spectra (Table 2) suggest that P atoms are present in samples $\mathrm{F}$ and I at approximately the distances observed in $\mathrm{U}_{2} \mathrm{O}\left(\mathrm{PO}_{4}\right)_{2}$ (cf., section SI-1). However, the EXAFSderived coordination number ratio of ca. 1:1 for the putative second and third shell $\mathrm{P}$ neighbors is inconsistent with the ratio of 1:4 expected for $\mathrm{U}_{2} \mathrm{O}\left(\mathrm{PO}_{4}\right)_{2}$. Thus, we conclude that, 


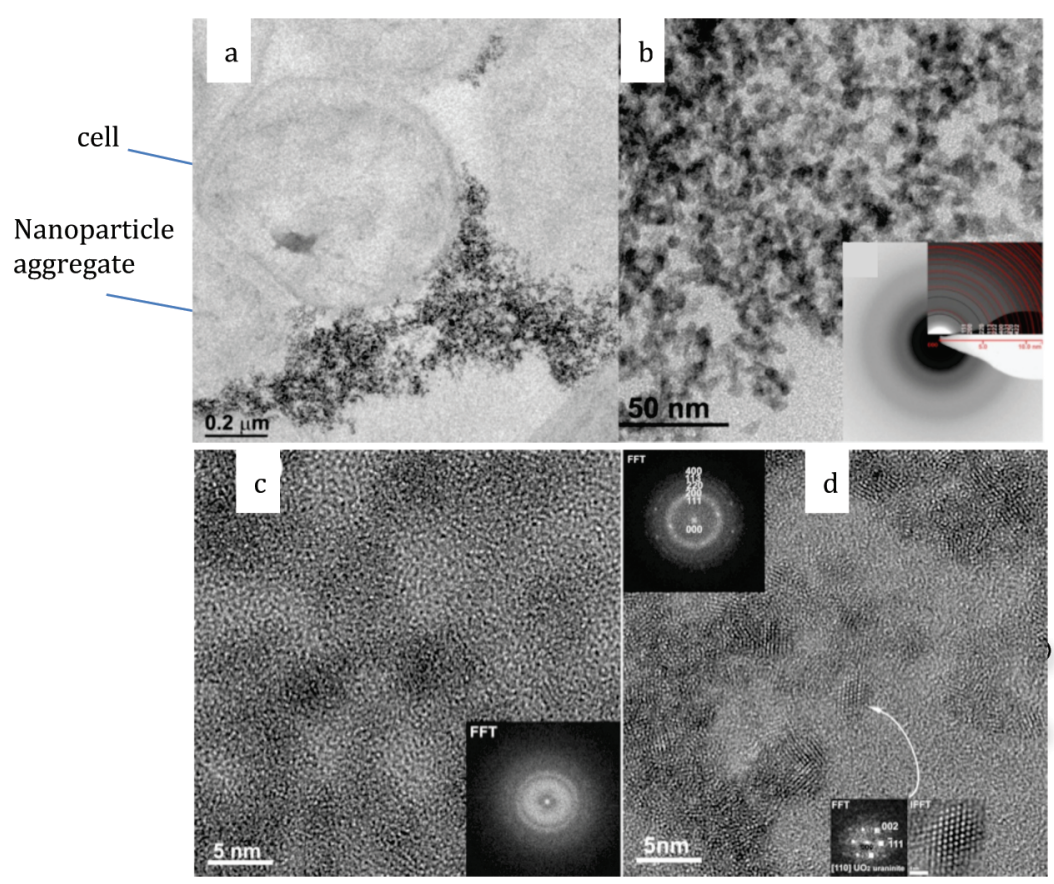

A. S. oneidensis cells in BP (sample A)

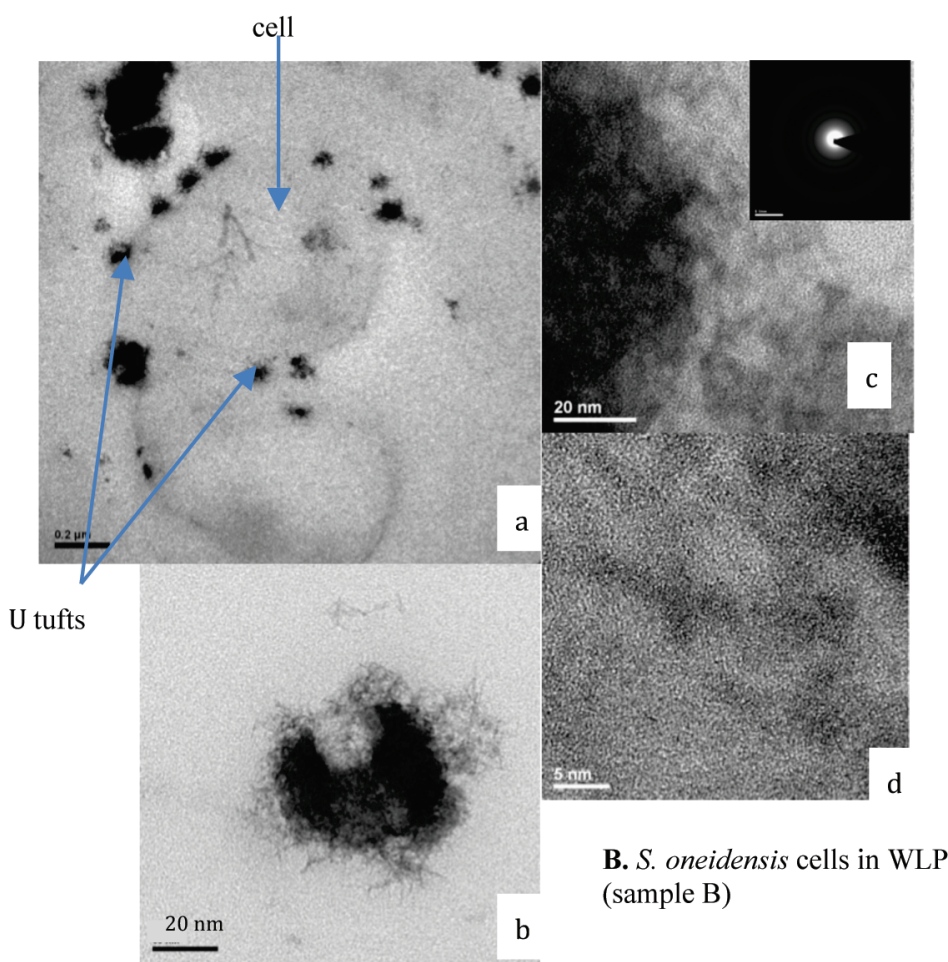

FIGURE 2. A. S. oneidensis in BP medium (sample A): TEM images of uraninite nanoparticles occurring as aggregates located away from the cell (a); magnified TEM image with the corresponding SAED pattern (b) interpreted as crystalline uraninite with particles of approximately $2.5 \mathrm{~nm}$ in diameter; HRTEM image of nanoparticles obtained during the first $2 \mathrm{~s}$ (c) and after $10 \mathrm{~s}$ (d) of electron irradiation. Sintering of uraninite particles is observed under prolonged exposure to the electron beam; the diffractogram (FFT) in the top left corner was obtained from the entire HRTEM image and interpreted as crystalline uraninite; the diffractogram and the filtered HRTEM image at the bottom right were obtained from a single crystalline particle of uraninite. B. $S$. oneidensis cells in fresh WLP medium (sample B): In contrast to sample A, reduced uranium has a tuft-like morphology as shown by TEM (a and b); a TEM image

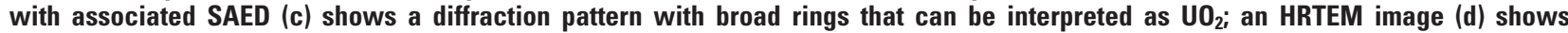
unstructured material (molecular U(IV)) even after long electron irradiation; there is no evidence for individual nanoparticles. The combined SAED and HRTEM results suggest that a small number of very small uraninite nanoparticles not detectable by HRTEM or XAS is present.

while this phase is detectable by electron microscopy techniques, it likely does not represent a large contribution to the overall sample.
Finally, detailed SAED analysis of sample $\mathrm{H}$ indicated that nanoparticles of $\mathrm{U}_{2}\left(\mathrm{PO}_{4}\right)\left(\mathrm{P}_{3} \mathrm{O}_{10}\right)$ were present (Figure SI-3B). This phase exhibits two $\mathrm{U}-\mathrm{P}$ pair distances: one at $3.27 \AA$ 
$(\mathrm{CN}=1)$ and another at $3.68-3.73 \AA(\mathrm{CN}=6)(29)$. However, since the $3.27 \AA \mathrm{U}-\mathrm{P}$ distance is not present in sample $\mathrm{H}$ (Table 2), we can conclude that this phase is not a major contributor to the U(IV) inventory in the sample.

Molecular U(IV). The analysis above indicates that samples for which $\mathrm{U}(\mathrm{VI})$ reduction took place in WLP medium (samples B, C, D, H, and I) lacked uraninite. Shell-by-shell fits of samples $B$ through I indicated the presence of $U-P$ and/or U-C pairs at $\sim 3.1 \AA$ and at $\sim 3.7 \AA$ that are not accounted for by any of the crystalline phases identified by HRTEM and SAED (Table 2). The presence of strong P/C shells, particularly at $3.1 \AA$, and the absence of a U-U peak is generally consistent with the presence of complexes of U(IV) with biomass surfaces. Furthermore, in samples prepared in WLP (samples B, H, and I), TEM and HRTEM indicated the presence of diffuse, nondiffracting $U$ assembled on 'tufts' associated with the cell wall or spore coat. The morphology of this U-containing material contrasts sharply with the observed uraninite or phosphate nanoparticles (Figure 2A). These observations lead to the conclusion that much of the $U(I V)$ in samples B through I is present as surface complexes on biomass. EDS data (Figure SI-4) show the systematic association of $U$ with $P$ in all the samples considered, suggesting that $\mathrm{P}$ groups are key coordination sites for the putative surface complexes. This conclusion is consistent with the observation that $\mathrm{P}$ neighbors provide good fits to the EXAFS data (Figure 1 and Table 2) but does not exclude the possibility that $U$ is also associated with C-containing groups.

Hereafter, we refer to this biomass-associated, nondiffracting species that lack a U-U EXAFS frequency as 'molecular U(IV)'. We conclude that molecular U(IV) (present as at least one and possibly multiple molecular species) is associated with the cell wall (cells) and exosporium (spores).

An additional piece of evidence of the fundamentally different nature of the Shewanella-derived U-containing material in samples B (molecular U(IV)) as compared to sample A (uraninite) is the effect of the electron beam on the sample. In the case of uraninite nanoparticles, sintering is observed with extended exposure to the beam (Figure 2A). In contrast, no sintering was detected in samples containing molecular U(IV), and thus this species is seemingly unaffected by the electron beam under the conditions used in this study (Figure 2B).

No amorphous precipitate is evident from electron microscopy, which is consistent with the conclusion that molecular U(IV) is a form of sorbed (rather than precipitated) U(IV). Results suggest an association with phosphate (and possibly carboxylate) moieties on the cell or spore surface layers.

Role of Medium Composition. As indicated previously, the absence of uraninite as a product of $\mathrm{U}(\mathrm{VI})$ reduction appears to be linked to the medium utilized. Differences in composition between the three media considered are mainly due to variations in the concentration of various mineral salts (Table SI-1). The simplest medium considered (BP) is composed of PIPES and bicarbonate, whereas the most complex (WLP) includes, in addition to those two constituents, salts such as $\mathrm{CaCl}_{2}, \mathrm{KCl}, \mathrm{MgCl}_{2}, \mathrm{NaCl}, \mathrm{NH}_{4} \mathrm{Cl}$, and $\mathrm{KH}_{2} \mathrm{PO}_{4}$. Thus, composition and ionic strength differ among the three media. As an example of the influence of medium composition on modulating the products of $\mathrm{U}(\mathrm{VI})$ reduction, S. oneidensis produces uraninite in BP medium (sample A) and molecular U(IV) in WLP (samples B, C, D) (Figure 2). Similarly, D. reducens cells and spores (samples H and I) for which the microbial reduction also occurs in WLP medium produce no uraninite (Figure 1, Figures SI-3A and SI-3B). Thus, none of the WLP-incubated samples showed evidence for the accumulation of uraninite as the product of reduction. C. acetobutylicum produces an intermediate product with some contribution from uraninite but that also includes molecular $\mathrm{U}(\mathrm{IV})$ and $\mathrm{U}_{2} \mathrm{O}\left(\mathrm{PO}_{4}\right)_{2}$. It is unclear whether the inhibition of uraninite formation in WLP is influenced by critical concentrations of specific ions, by ionic strength or a combination of these effects. An alternative explanation for uraninite inhibition is that $\mathrm{U}(\mathrm{VI})$ sorption to biomass is strongly enhanced in WLP medium (Figure SI-1- open vs filled triangles) and that sorbed U(VI) remains bound to functional groups on the cell biomass during reduction, mechanistically eliminating the precipitation of uraninite. However, at present, we are unable to resolve the mechanism of this inhibition.

Environmental Implications. Most studies of microbial $\mathrm{U}(\mathrm{VI})$ reduction have focused on the production of uraninite, often inferred or assumed to be the main product in geochemical models (24). Our findings suggest that chemical conditions - particularly the presence of various solutes- may inhibit the biologically mediated formation of uraninite. The mechanism of this inhibition is unknown. However, in the presence of these inhibitory factors, U(IV) appears to be primarily associated with phosphate and/or carboxylate groups from the cell membrane. In the case of $D$. reducens spores, a ningyoite-like phase forms as an additional, if minor, product, whereas in the case of C. acetobutylicum, a $\mathrm{U}_{2} \mathrm{O}\left(\mathrm{PO}_{4}\right)_{2}$ phase is observable.

Differences in the contributions of the various $\mathrm{U}-\mathrm{P}$ shells for each sample coupled to the observation of the nonuraninite phases point to variability in the nature of the U(IV) products. While geochemical conditions appear to significantly influence the microbially mediated formation of uraninite, biological variability also contributes to the nature of the product. These results suggest that there is a wealth of U(IV) chemistry not fully understood in these systems and that there may be complex mixtures of U(IV) products in the field. As a result, we predict that in the subsurface, where groundwater typically contains various solutes and can range in ionic strength and composition, the product of microbial $\mathrm{U}(\mathrm{VI})$ reduction may not be dominated by uraninite. Additional products such as molecular U(IV) would have an important impact on U(VI) bioremediation because these species may have significantly different chemical properties, compositions, and responses to evolving solute conditions than uraninite. A thorough understanding of the structures, compositions, occurrence, and stabilities of these species is crucial to describe and model reductive natural attenuation processes and to improve in situ reductive approaches to uranium remediation.

\section{Acknowledgments}

We thank J. E. Stubbs for her help in running samples and improving this manuscript. The work was funded by Swiss NSF grants \#20021-113784, \#IZK0Z2-123550, and \#3100A0112337; U.S. Department of Energy (DOE), Office of Biological and Environmental Research (OBER) \#DE-FG02-06ER64227 and \#SCW0041; Roche Research Foundation fellowship to E.D.V.; DOE-OBER, Subsurface Environmental systems Science Program grant to SLAC-SFA program work package number 2009-SLAC-10006. SSRL is a national user facility operated by Stanford University on behalf of the US DOE BES. The Interdisciplinary electron microscopy center at EPFL provided electron microscopy facilities.

\section{Supporting Information Available}

Additional details EXAFS fitting, basal media composition, vitamin and trace element composition, $\mathrm{U}(\mathrm{VI})$ reduction profiles, XANES, electron micrographs, and EDS maps and spectra. This material is available free of charge via the Internet at http://pubs.acs.org. 


\section{Literature Cited}

(1) Lovley, D. R.; Phillips, E. J. P.; Gorby, Y. A.; Landa, E. R. Microbial reduction of uranium. Nature 1991, 350, 413-416.

(2) Gorby, Y. A.; Lovley, D. R. Enzymatic uranium precipitation. Environ. Sci. Technol. 1992, 26 (1), 205-207.

(3) Lovley, D. R.; Phillips, E. J. P. Reduction of uranium by Desulfovibrio desulfuricans. Appl. Environ. Microbiol. 1992, 58, 850-856.

(4) Wu, Q.; Sanford, R. A.; Loffler, F. E. Uranium(VI) reduction by Anaeromyxobacter dehalogenans strain 2CP-C. Appl. Environ. Microbiol. 2006, 72 (5), 3608-3614.

(5) Suzuki, Y.; Kelly, S. D.; Kemner, K. M.; Banfield, J. F. Nanometresize products of uranium bioreduction. Nature 2002, 419 (6903), 134-135.

(6) Kelly, S. D.; Wu, W. M.; Yang, F.; Criddle, C. S.; Marsh, T. L.; O’Loughlin, E. J.; Ravel, B.; Watson, D.; Jardine, P. M.; Kemner, K. M. Uranium transformations in static microcosms. Environ. Sci. Technol. 2010, 44 (1), 236-242.

(7) Kelly, S. D.; Kemner, K. M.; Carley, J.; Criddle, C. S.; Jardine, P. M.; Marsh, T.; Phillips, D.; Watson, D.; Wu, W. M. Speciation of uranium in sediments before and after in situ biostimulation. Environ. Sci. Technol. 2008, 42 (5), 1558-1564.

(8) Ulrich, K. U.; Singh, A.; Schofield, E. J.; Bargar, J. R.; Veeramani, H.; Sharp, J. O.; Bernier-Latmani, R.; Giammar, D. E. Dissolution of biogenic and synthetic $\mathrm{UO}_{2}$ under varied reducing conditions. Environ. Sci. Technol. 2008, 42 (15), 5600-5606.

(9) Schofield, E. J.; Veeramani, H.; Sharp, J. O.; Suvorova, E.; BernierLatmani, R.; Mehta, A.; Stahlman, J.; Webb, S. M.; Clark, D. L.; Conradson, S. D.; Ilton, E. S.; Bargar, J. R. Structure of biogenic uraninite produced by Shewanella oneidensis strain MR-1. Environ. Sci. Technol. 2008, 42 (21), 7898-7904.

(10) Sharp, J. O.; Schofield, E. J.; Veeramani, H.; Suvorova, E. I.; Kennedy, D. W.; Marshall, M. J.; Mehta, A.; Bargar, J. R.; BernierLatmani, R. Structural similarities between biogenic uraninites produced by phylogenetically and metabolically diverse bacteria. Environ. Sci. Technol. 2009, 43 (21), 8295-8301.

(11) Khijniak, T. V.; Slobodkin, A. I.; Coker, V.; Renshaw, J. C.; Livens, F. R.; Bonch-Osmolovskaya, E. A.; Birkeland, N. K.; MedvedevaLyalikova, N. N.; Lloyd, J. R. Reduction of uranium(VI) phosphate during growth of the thermophilic bacterium Thermoterrabacterium ferrireducens. Appl. Environ. Microbiol. 2005, 71 (10), 6423-6426.

(12) Gao, W. M.; Francis, A. J. Reduction of uranium(VI) to uranium(IV) by Clostridia. Appl. Environ. Microbiol. 2008, 74 (14), $4580-4584$.

(13) Fletcher, K. E.; Boyanov, M. I.; Thomas, S. H.; Wu, Q.; Kemner, K. M.; Loeffler, F. E. U(VI) reduction to mononuclear U(IV) by Desulfitobacterium species. Environ. Sci. Technol. 2010, 44 (12), 4705-4709.

(14) Francis, A. J.; Dodge, C. J.; Lu, F.; Halada, G. P.; Clayton, C. R. XPS and XANES studies of uranium reduction by Clostridium sp. Environ. Sci. Technol. 1994, 28, 636-639.
(15) Widdel, F.; Bak, F., Gram-negative mesophilic sulfate-reducing bacteria. In The Prokaryotes; Ballows, A., Truper, H. G., Dworkin, M., Harder, W., Shleifer, K.-H., Eds.; Springer: Berlin, 1992; Vol. 4, pp 3352-3378.

(16) Veeramani, H.; Schofield, E. J.; Sharp, J. O.; Suvorova, E. I.; Ulrich, K. U.; Mehta, A.; Giammar, D. E.; Bargar, J. R.; Bernier-Latmani, R. Effect of Mn(II) on the Structure and Reactivity of Biogenic Uraninite. Environ. Sci. Technol. 2009, 43 (17), 6541-6547.

(17) Junier, P.; Frutschi, M.; Wigginton, N. S.; Schofield, E. J.; Bargar, J. R.; Bernier-Latmani, R. Metal reduction by spores of Desulfotomaculum reducens. Environ. Microbiol. 2009, 11 (12), 3007-3017.

(18) APWA. Standard Methods for the examination of water and wastewater, 20th ed.; Denver, CO, 1998.

(19) Ames, B. N. Assay of inorganic phosphate, total phosphate and phosphatase. In Methods in Enzymology; Neufield, E. F., Ginsburg, V., Eds.; Academic Press: New York, London, 1966; Vol. 8, pp 115-118.

(20) Stadelmann, P. http://cimewww.epfl.ch/people/stadelmann/ jemswebsite/jems.html (accessed April 4, 2010).

(21) Ravel, B.; Newville, M. ATHENA, ARTEMIS, HEPHAESTUS: data analysis for X-ray absorption spectroscopy using IFEFFIT. $J$. Synchrotron. Radiat. 2005, 12, 537-541.

(22) Rehr, J. J.; Albers, R. C.; Zabinsky, S. I. High-order multiplescattering calculations of x-ray absorption fine structure. Phys. Rev. Lett. 1992, 69 (23), 3397-3400.

(23) Singer, D. M.; Farges, F.; Brown, G. E. Biogenic nanoparticulate UO2: Synthesis, characterization, and factors affecting surface reactivity. Geochim. Cosmochim. Acta 2009, 73 (12), 3593-3611.

(24) Yabusaki, S. B.; Fang, Y.; Long, P. E.; Resch, C. T.; Peacock, A. D.; Komlos, J.; Jaffe, P. R.; Morrison, S. J.; Dayvault, R. D.; White, D. C.; Anderson, R. T. Uranium removal from groundwater via in situ biostimulation: Field-scale modeling of transport and biological processes. J. Contam. Hydrol. 2007, 93 (1-4), 216235.

(25) Fowle, D. A.; Fein, J. B.; Martin, A. M. Experimental study of uranyl adsorption onto Bacillus subtilis. Environ. Sci. Technol. 2000, 34 (17), 3737-3741.

(26) Dusausey, Y.; Ghermani, N. E.; Podor, R.; Cuney, M. Lowtemperature ordered phase of $\mathrm{CaU}\left(\mathrm{PO}_{4}\right)_{2}$ : synthesis sand crystal structure. Eur. J. Mineral. 1996, 8, 667-673.

(27) Huang, S. S.; Chen, D.; Pelczar, P. L.; Vepachedu, V. R.; Setlow, P.; Li, Y. Q. Levels of Ca2+-dipicolinic acid in individual Bacillus spores determined using microfluidic raman tweezers. $J$. Bacteriol. 2007, 189 (13), 4681-4687.

(28) Benard, P.; Louer, D.; Dacheux, N.; Brandel, V.; Genet, M. Synthesis, ab initio structure determination from powder diffraction and spectroscopic properties of a new diuranium oxide phosphate. An. Quim. Int. Ed. 1996, 92, 79-87.

(29) Podor, R.; Francois, M.; Dacheux, N. Synthesis, characterization and structure determination of the orthorhombic $\mathrm{U}_{2}\left(\mathrm{PO}_{4}\right)\left(\mathrm{P}_{3} \mathrm{O}_{10}\right)$. J. Solid State Chem. 2003, 172, 66-72.

ES101675A 